Original article

\title{
Analysis of Trends of the Types of Pesticide Used, Residues and Related Factors among Farmers in the Largest Vegetable Producing Area in the Philippines
}

\author{
Jinky Leilanie Lu \\ National Institutes of Health, University of the Philippines Manila, Manila, Philippines
}

\begin{abstract}
The objective of study is to provide an analysis of data trends on the type of pesticide used, exposure factors, and the pesticiderelated concerns among the farmers from 2005 to 2010 in one of the largest vegetable producing areas in the Philippines. This is to determine and analyze changes that have occurred for the last five years in order to provide necessary basis in promoting safe usage of pesticides. It is shown in the studies that the most commonly used type of pesticide was Tamaron (methamidophos) which is an organophosphate. The top five pesticide-related symptoms confirm findings in other studies. The risk factors to pesticide exposure were also identified in the reviewed studies such as improper mixing and loading of pesticides, and re-entering previously sprayed area. Pesticide residues were also found in vegetables, soil and water samples. This points to environmental contamination due to pesticide. It is suggested that government agencies implement programs on monitoring, surveillance, information dissemination, and training on proper use of pesticides, and seek alternative farming such as organically grown vegetables, or use of integrated pest management as well as good agricultural practices.
\end{abstract}

Key words: pesticides, pesticide residues, vegetable farmers, occupational health

(J Rural Med 2010; 5(2): 184-189)

\section{Introduction}

Agriculture is one of the primary contributors to the Philippine's (GDP) gross domestic product. It is a source of income and subsistence among many Filipinos. In agriculture, competition is high on the quality and number of food production. Likewise, there is an increasing demand for

Correspondence to: Jinky Leilanie Lu

National Institutes of Health, University of the Philippines Manila,

NIH Bldg, P. Gil Street, Ermita, Manila, Philippines 1100

E-mail: jinky_lu@yahoo.com food production for the increasing number of population in the country. As such, farmers tend to rely on extensive use of pesticides to increase yield. Consequently, health of most of the agricultural workers is being compromised. There are many studies documenting the relationship between pesticide use and its effect on the farmer's health. Chronic effects of pesticide exposure include cancer in adults and children, adverse reproductive outcomes, delayed neuropathy and neurobehavioral effects ${ }^{1)}$. People who are directly exposed to pesticides are the handlers who mix, load and apply pesticides, and workers cultivating and harvesting crops. They are at risk of developing acute poisoning or even death from extensive exposures ${ }^{1)}$.

In 2009, the Gross National Product (GNP) of the country grew about $4.01 \%$ from the previous year. In the same year, the Gross Domestic Product (GDP) increased by $1.06 \%$ and the Gross Value Added (GVA) in agriculture and fishery expanded by $0.03 \%$. The agricultural and fishery sector accounted for $18 \%$ of the GDP in 2009 . Of the total labor force employed at 35.06 million persons, 12.04 million persons were employed in agricultural sector, and contributed $34 \%$ to the national employment ${ }^{2}$.

The Cordillera Administrative Region (CAR) supplies most of the commercial vegetable and other agricultural crops in the Philippines ${ }^{3)}$. Benguet is one of the provinces in this region.

Benguet province has a land area of about $2,599.4 \mathrm{~km}^{2}$ and a population of 372,533 . The agricultural land in Benguet covers about 30 thousand hectares with 27.5 thousand farms. Benguet primarily cultivates crops such as tubers, roots, bulbs, and leafy vegetables, stems, and flowers that makes it popularly known as the "salad bowl" of the country. Moreover, Benguet province is the country's top cabbage producer. This region contributed 77.0 percent to the country's production of cabbage in the first 3 months of $2010^{2)}$.

The objective of the study is to provide trends regarding 


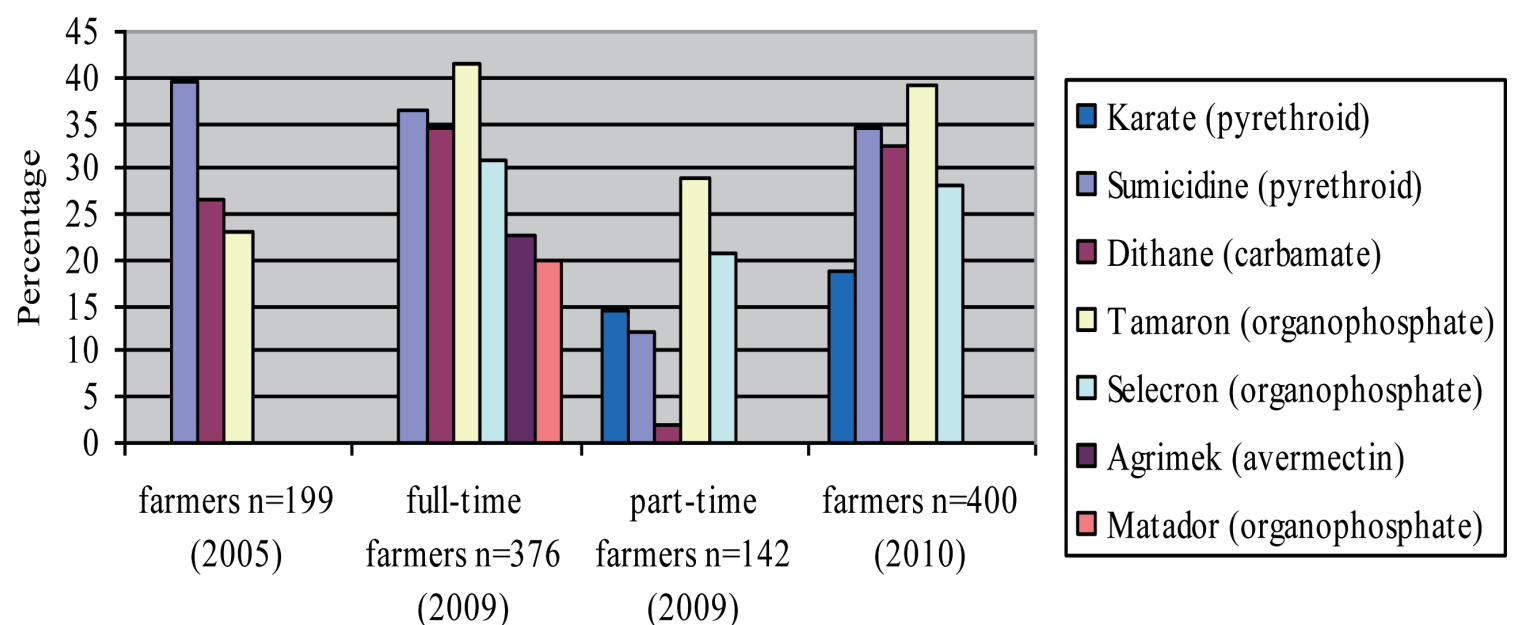

Figure 1 Percentage distribution of types of pesticide (brand name and corresponding active ingredient), 2005-2010 ${ }^{3-6}$.

the type of pesticide used by the Benguet farmers according to types, risk factors to pesticide exposure, work practices, and pesticide residues in environmental samples.

\section{Methods and Materials}

The data for this study were gathered from research studies about agricultural practices and pesticide use in Benguet. Researches of $\mathrm{Lu}^{3-6)}$ primarily discussed pesticide use and exposure of the farmers, as well as pesticide residues found in vegetables, water and soil, and occupational health-related risk factors in Benguet province.

Data from other agencies were reviewed, compared and analysed. These data came from the Bureau of Plant Industry, Department of Agriculture, Bureau of Agricultural Research, Department of Health, the Department of Science and Technology, Univeristy of the Philippines Manila, University of the Philippines Los Banos, and Benguet State University.

\section{Results}

The study focused on creating data trends of the types of pesticides used, and pesticide-related risk factors associated with pesticide exposure from 2005 to 2010 . The respondents were the farmers of Benguet interviewed from the year 2005 to 2010 .

There are three major types of pesticides being used by Benguet farmers according to chemical composition. These are pyrethroids, organophosphates, and carbamates. Pyrethroids are synthetic (human-made) forms of pyrethrins. Pyrethrins are insecticides that are derived from the extract of chrysanthemum flowers. The plant extract, called pyrethrum contains pyrethrin that is widely used for control of various insect pests. Examples of pyrethroids used by the farmers in the study area were cypermethrin, cyfluthrin, deltamethrin, cyphenothrin, fenvalerate, and fluvalinate. Organophosphates are chemical substances originally produced by the reaction of alcohols and phosphoric acid. They function as cholinesterase inhibitors, thereby affecting neuromuscular transmission ${ }^{7)}$. Examples of organophosphates found to be commonly used by the farmers were malathion, parathion, diazinon, fenthion, dichlorvos, chlorpyrifos, and ethion ${ }^{8)}$.

Figure 1 shows the trend of the pesticides used by their brand names. Tamaron (methamidophos) was the most prevalent type of pesticide used by the Benguet farmers. This type of pesticide is an organophosphate pesticides. Dithane (mancozeb) which is a dithiocarbamate was the second most prevalent type of pesticide used. This was followed by Sumicidine (fenvalerate) which is a pyrethroid.

Pyrethroid, however, was the most common type of pesticides that caused acute pesticide poisoning in the year 2009 to 2010 as documented by the National Poison Control and Management Center (NPCMC). See Figure 2. This was followed by carbamates and then organophosphates.

\section{Health related complaints due to pesticides}

Health complaints of the farmers are related to their working behavior and farming practices ${ }^{3)}$. Muscle pain was the most frequently experienced health symptoms of the farmers. This was statistically associated with the use of damaged backpack sprayer, incorrect design of backpack sprayer, and spraying against the wind. Farmers who used 


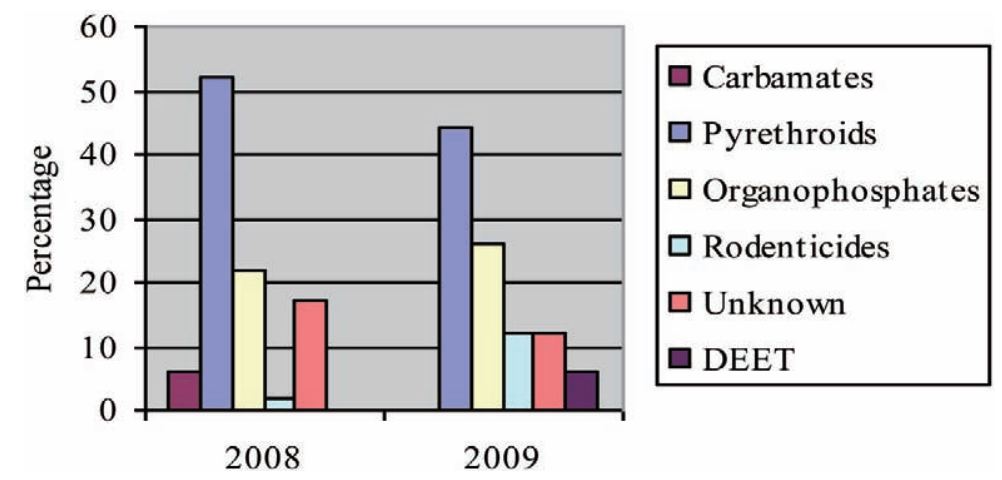

Figure 2 Percentage distribution of types of pesticides ${ }^{8)}$.

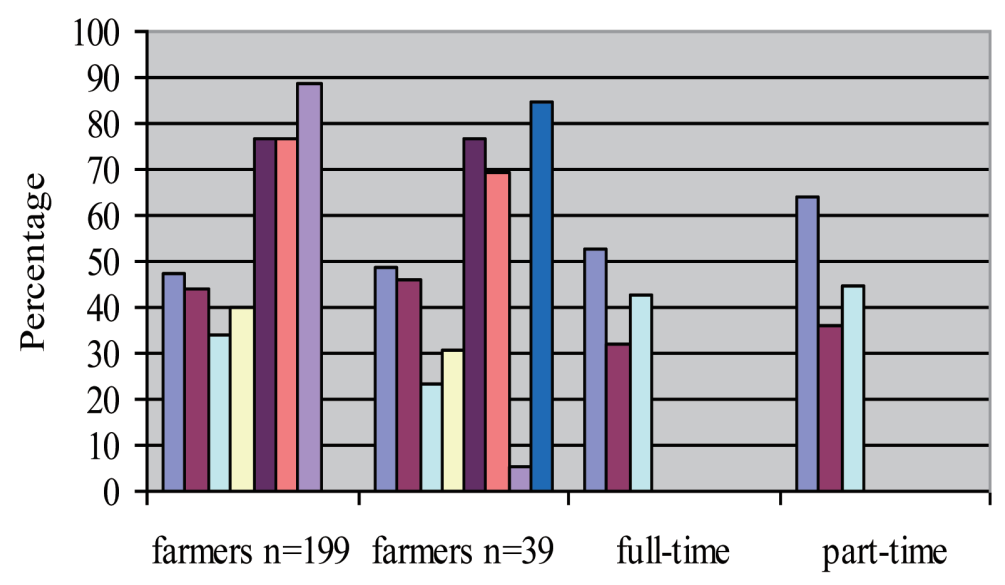

(2005) farmers $n=376$ farmers $n=142$

(2009)

(2009)
Wiping sweat with residuecontaminated cloth

Re-entering sprayed area

$\square$ Spraying against the wind

\section{$\square$ Damaged backpack sprayer}

Spills and splashes while spraying

$\checkmark$ Spills due to loading

$\square$ Eating while working

Figure 3 Percentage distribution of risk factors and work practices that maybe associated with pesticide exposure ${ }^{3-6)}$.

damaged backpack sprayer were 2.48 times more likely to experience muscle pain. Also, those who sprayed against the wind were 3.14 times more likely to experience muscle pain than those who correctly sprayed.

The pesticide-related symptoms experienced by the farmers were muscle pain, fatigability, weakness and eye irritation $^{4,5)}$ which are similar to those reported by other researchers $^{12,14,18)}$.

\section{Risk factors to pesticide exposure}

Figure 3 shows the risk factors when using pesticides. The most common risk factors were wiping sweat with a residue- contaminated piece of fabric, entering recently sprayed area, and spraying against the wind. These three factors were associated with greater pesticide exposure in $2010^{3)}$.

\section{Pesticide residue in soils}

In a study in farming areas in Benguet conducted by $\mathrm{Lu}^{6}$, positive results of pesticide residues were obtained in soil samples. Of the 78 soil samples, 34 were found to be positive for pesticide residues. The specific residue types were endosulfan sulfate, profenofos, chlorothalonil, T endosulfan, chlorpyrifos, cypermerthrin, and cyhalothrin. Chlorothalonil with a concentration of $0.13 \%$ in the soil samples at a $0.002 \mathrm{mg} / \mathrm{kg}$, is a chloronitrile. It is a broadspectrum OC fungicide and is degraded more rapidly at higher temperatures and when soil moisture is increased. Chlorpyrifos, which is an organophosphate, was found in $27.4 \%$ of soil samples at $0.01 \mathrm{mg} / \mathrm{kg}$ concentration.

Pesticide residues in water

In the study of $\mathrm{Lu}(2009)^{6}$, , one water sample was found 


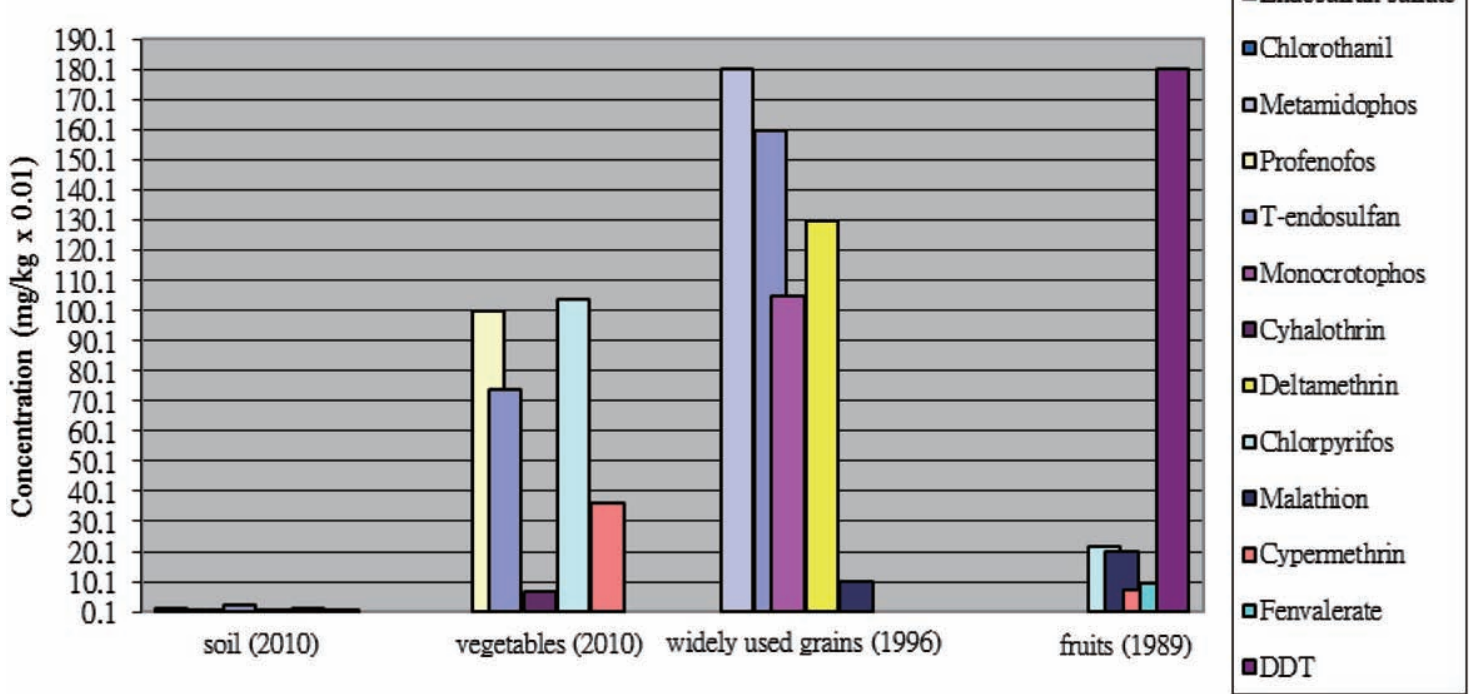

Figure 4 Concentration of pesticide residues $(\mathrm{mg} / \mathrm{kg} \times 0.01)$ in soils, vegetables, fruits, and widely used grains ${ }^{10-12)}$.

positive with pesticide residue of chlorpyrifos with a concentration of $0.7 \mu \mathrm{g} / \mathrm{L}$. This value exceeded the ambient water concentration set by the Environmental Protection Agency (EPA) set for freshwater in both acute $(0.083 \mu \mathrm{g} / \mathrm{L})$, and chronic situations $(0.041 \mu \mathrm{g} / \mathrm{L})$. Thus, this value may indicate that the level of pesticide in the creek is toxic to aquatic life forms.

\section{Pesticide residues in crops}

Figure 4 shows the prevalence of pesticide residues in soil, fruits, vegetables and widely used grains. In one study of $\mathrm{Lu}^{3)}$, pesticide residues such as chlropyrifos and profenofos were present in soil samples. This is also a risk to the children since their breathing zone is nearer to the ground and they maybe in direct contact with the soil when playing. $\mathrm{Lu}$ also reported that soil contamination with organochlorine pesticides such as endosulfan has aroused worldwide concerns considering their high toxicities and long-term persistence. Another study of Lu reported that vegetables, primarily those that are from Benguet were detected for the presence of pesticide residues ${ }^{10)}$. Pesticide residue in the vegetable samples was found in $16.67 \%$ of the total samples submitted. Chlorpyrifos was the most common pesticide residue found.

Saldivar also studied pesticide residues found in vegetables, widely used grains, and fruits ${ }^{11)}$. She noted that farmers still continue to use banned pesticides such as chlorinated hydrocarbons, endosulfan, methyl parathion, azinphos ethyl, DDT (dichlorodiphenyltrichloroethane) and restricted chemicals like monocrotophos in their crop protection measures ${ }^{11)}$.
Among the crops receiving frequent spraying of insecticide and fungicide treatments were cabbage, tomatoes, baguio beans, pechay, string beans, ampalaya, bell pepper and rice. Residues of metamidophos and malathion way above Allowable Daily Intake (ADI) were detected in some samples of tomato, ampalaya, eggplant, bell pepper and baguio beans. Rola reported carbofuran and 3-OH residues in rice plant and its grains ${ }^{12)}$. Moreover, cypermethrin residue was found in string beans, and fenvalerate residues in peanuts and soybeans.

\section{Discussion}

In the Philippines, pesticides are widely used by farmers. The three most common types of insecticides are organophosphates, carbamates and pyrethoids. The three most important crops that use pesticides are vegetables, banana and rice. At present, the country has implemented the Integrated Pesticide Management to regulate the use of pesticides in the country ${ }^{13)}$.

\section{Types of pesticide used}

Based on the results above, Tamaron (methamidophos) had been the most frequently used pesticides in the years 2004 to 2009. Tamaron is an organophosphate type of pesticides. Organophosphate has been the causative chemical agent of many of the reported pesticide related illnesses in the US ${ }^{14)}$. In countries such as India and Nicaragua, organophosphates are easily accessible and, therefore, source of both intentional and unintentional poisonings ${ }^{15)}$. In China, it 
was found that the milled rice from the local market had pesticide residue of organophosphates ${ }^{16)}$. Next to Tamaron, Dithane (mancozeb) which is a dithiocarbamate was also commonly used by Benguet farmers.

Tamaron is a category I pesticide containing the organophosphate methamidophos and diethylene glycol. Tamaron, as an organophosphate pesticide can function as cholinesterase inhibitor. It affects neuromuscular transmission ${ }^{15}$. Dithane which is a category IV dithiocarbamate pesticide contains mancozeb as its active ingredient. Its toxicity manifests in tearing of the eyes, blurred vision, and irritation of throat and nose $\mathrm{e}^{15)}$.

\section{Pesticide-related health complaints}

In comparing the studies of Penagos et al. in 2004 ${ }^{17)}$ among the banana farmers and the studies of $\mathrm{Lu}^{6,3)}$, the pesticides chlorothalonil and chlorpyrifos were both used by the Benguet farmers and the Latin American farmers. It was documented in the study of Penagos et,al that the farmers experienced dermatoses due to chlorpyrifos. Likewise, Benguet farmers reported skin itchiness due to this pesticide. Furthermore, Nagami in 2010 noted that farm-work related diseases were dermal and allergic in nature among the Japanese ${ }^{15)}$. Other pesticides such as mancozeb and chlorothalonil that were used by the Benguet farmers were also found to be ubiquitous pesticides in Costa Rica ${ }^{18)}$.

The studies of $\mathrm{Lu}^{3-5}$ documented the risk factors associated with pesticide exposure. These were re-entering recently sprayed area, spraying against the wind, use of damaged backpack sprayer, spills on the back, spills while mixing pesticides, and wiping sweat on face with residuecontaminated piece of fabric. Benguet farmers as well as the farmers from India use backpack sprayer due to its easy availability and suitability for their crops in spraying ${ }^{19}$.

Improper work practices were found similar in Benguet and Nicaragua as reported by $\mathrm{Lu}^{3)}$ and Blanco et al. ${ }^{20)}$. These work practices involve the spraying against the wind, no labeling of the pesticide container, and spilling of pesticides while spraying.

In the study among Benguet farmers, the back was spilled with pesticide due to leaks from the backpack sprayer. In the study of Aragon et al. in 2006 among Nicaraguan farmers, the hands were the most frequently contaminated, and the back had the highest body segment score due to leaking backpack sprayers. This calls for a redesign of the backpack sprayer, and preventive mechanisms for leaks in backpacks.

\section{Pesticide residues}

The study of Lu showed pesticide residues in crops, soil and water samples in Benguet ${ }^{3,10)}$. Similarly, the study of
Rola showed that farmer's practice with respect to frequency of insecticide application on their crops was somewhat alarming ${ }^{12)}$. Researchers observed that the farmers sprayed more frequently at the peak of harvesting, such that farmers would spray their pole sitao almost every other day. They also witnessed how farmers dipped their harvested vegetables such as sitao and okra in formalin so that these would be greener and crispier. In Benguet, some vegetables analyzed were found with different kinds of pesticide residues, some of which are already restricted such as endosulfan.

This study of Rola also showed that the pesticides detected in cabbage were diazinon, lindane, endosulfan, methyl parathion, heptachlor and dieldren ${ }^{12)}$. The last three pesticides mentioned are banned for use in vegetables. These pesticides are to be for termite use only. Furthermore, the Codex MRL of $0.2 \mathrm{mg} / \mathrm{kg}$ for methyl parathion was exceeded in $22 \%$ of tomato samples.

Despite being one of the banned pesticides by the Fertilizer and Pesticide Authority, DDT was still used and detected in vegetables such as string beans, eggplants, onions, carrots, sweet peas, pepper, celery, and mustard. Other restricted pesticides such as pesticides aldrin, dieldren, chlordane and heptachlor were also found in Benguet grown vegetables ${ }^{10)}$. In Manila, the use of endrin in string beans and other vegetables, the use of DDT in tomatoes, and the use of non-registered pesticides in some crops were detected $^{11)}$. Antazo (1986) noted that there is an increasing occurrence of DDT, endrin, and methyl parathion residues in vegetables inspite of an existing FPA ban on their use ${ }^{12)}$.

\section{Conclusion}

The various studies conducted in Benguet province which is the largest vegetable producer in northern Philippines have shown data and trends on use of pesticides by the farmers in the area as documented over the years. The various studies showed the risk factors associated with pesticide exposure, health complaints commonly found among farmers and pesticide applicators, and work practices that predispose farmers to pesticide exposure. The studies also showed the presence of pesticide residues in the environment and agricultural crops. The trending of pesticide residues in this study should be used by the local and national government to monitor regulation on the use of banned and restricted pesticides in the province of Benguet.

The trending done in this study gives way to promote awareness to the community and government agencies regarding overuse of pesticides, or use of banned and restricted types, as well as the adverse effects of pesticides on humans and the environment. It is suggested that the Fertilizer and Pesticide Authority in the Philippines be more 
effective in implementing restrictions in the use of banned and restricted pesticides. It is also recommended that massive information campaign be conducted among the farmers concerned on correct use of pesticides, and the deleterious effects of overuse and misuse of pesticides on humans and the environment. Safer and alternative methods of growing healthy and safe crops should also be encouraged and promoted.

\section{References}

1. Moses M. Pesticide-related health problems and farmworkers. AAOHN J 1989; 37: 115-130.

2. Bureau of Agricultural Statistics. Crop Statistics. 2010 Available [online]: http://www.bas.gov.ph

3. Lu J. Multi-pesticide residue assessnment of agricultural soil and water in major farming areas in Benguet, Philippines, AECT-Multi pesticides 2010.

4. $\mathrm{Lu} \mathrm{J}$. Pesticides exposure, risk factors and health problems among vegetable farm workers 2005 (unpublished journal).

5. Lu J. Pesticide exposure: risk factors and health problems among vegetable farm workers, Acta Medica 2006; 40: 4-6.

6. $\mathrm{Lu} \mathrm{J}$. Comparison of pesticide exposure and physical examination, neurological assessment and laboratory findings between full-time and part-time vegetable farmers in the Philippines. Environ Health Prev Med 2009.

7. Dyro F. Organophosphates. Department of Neurology, New York Medical College, Westchester Medical Center 2009.

8. Katz K. Toxicity, Organophosphate. Department of Emergency Medicine, University of Pittsburgh Medical Center 2010.

9. National Poison Control and Management Center, 2009.

10. $\mathrm{Lu} \mathrm{J}$. Investigation of pesticide residue in vegetables and occupational safety of farmers in the vegetable industry, 2010 (in print).

11. Saldivar E. Studies on pesticide residues of widely used grains, vegetables and fruits. Department of Agriculture II Central Mindanao Integrated Agricultural Research Center 1996.

12. Rola A. Pesticides, health risks and farm productivity: a philippine experience. UPLB. 1989.

13. Navarro RL, Medina JR, Callo DP. Empowering farmers: The Philippine National Integrated Pest Management Program. SEAMEO-SEARCA 1998. UPLB College, Laguna.

14. American Association of Poison Control Centers, 2007.

15. Nagami H. Historical perspective of pesticide poisoning in japan and measures taken by the Japanese Association of Rural Medicine. J Rural Med 2010; 5: 129-133.

16. Chen $\mathrm{C}$, Li Y, Chen M, et al. Organophosphorus pesticide residues in milled rice (Oryza sativa) on the Chinese market and dietary risk assessment. Food Addit Contam Part A Chem Anal Control Expo Risk Assess. 2009; 37: 340-347.

17. Penagos H, Ruepert C, Partanen T. et al. Pesticide patch test series for the assessment of allergic contact dermatitis among banana plantation workers in Panama. Am J Contact Dermat 2004; 15: 137-145.

18. Partanen T, Chaves J, Wesseling C. et al. Workplace carcinogen and pesticide exposures in Costa Rica. Int J Occup Environ 2003; 9: 104-111.

19. Singh B, Gupta M. Pattern of use of personal protective equipments and measures during application of pesticides by agricultural workers in a rural area of Ahmednagar district, India. Bull Environ Contam Toxicol 2009; 13: 127-130.

20. Blanco LE, Aragón A, Lundberg I, et al. Determinants of dermal exposure among Nicaraguan subsistence farmers during pesticide applications with backpack sprayers. Ann Occup Hyg, 2005; 49: 17-24. 